\title{
PLASTIC MATERIALS IN EUROPEAN AGRICULTURE: ACTUAL USE AND PERSPECTIVES
}

\author{
Giacomo Scarascia-Mugnozza, Carmela Sica, Giovanni Russo
}

\section{The diffusion of plastic materials in the agricultural sector}

The continuous innovation of polymeric technology and manufactured plastic helps to explain that, since 1950 , plastic production has increased on an average of almost $10 \%$ every year on a global basis. From around 1.3 million tons in 1950 the total global production of plastic has grown to 225 million tons in 2004 [PlasticsEurope 2006] This great diffusion, due to some peculiar characteristics of the plastic material, such as lightness, strength, workability and low cost, concerned all different productive sectors, including the agricultural one.

The world consumption of plastics in agriculture amounts yearly to 6.5 million tons. In particular, the use of plastic materials in agriculture was first introduced in 1948 in the U.S.A. to cover some little greenhouses with cellophane and, immediately after, using PVC to cover greenhouses in Japan. It has progressively expanded over the years in many countries and for several applications, replacing traditional materials such as glass to cover greenhouses and paper or straw for soil mulching [Picuno 1994].

\section{Agricultural applications of plastics}

An extensive and steadily expanding use of plastic films in agriculture (Tab. 1) and particularly in protected horticulture is reported world-wide since the middle of the twentieth century.

Some of the reported benefits of using plastic materials in agricultural fields result from increased

Paper received 22.11.2010; accepted 08.07.2011

G. Scarascia-MugnozZA, full Professor - Dept. DISAAT, University of Bari Aldo Moro, Via G. Amendola n.165/a - 70126 Bari, Italy. E-mail: scarasci@agr.uniba.it. C. SICA, Researcher - Dept DITEC,University of Basilicata - Potenza, c.da Macchia Romana 85100 Potenza, Italy. G. Russo, Researcher - Dept. DISAAT, University of Bari Aldo Moro, Via G. Amendola n.165/a - 70126 Bari, Italy.

The Contribution to programming and executing this research must be equally shared among the Authors. yields, earlier harvests, reduction of herbicide and pesticide consumption, frost protection and water conservation, without leaving out the importance of plastic material in order to preserve, transport, package and commercialize agro-food products. It has also provided a more efficient use of farm land, higher quality of crops and a resultant healthier environment.

Furthermore, plastics-based agricultural systems provide effective solutions for crop growing in many ways: in arid regions, for example, plastic irrigation tapes, piping and drainage systems can cut irrigation costs by one to two-thirds, while as much as doubling crop yield. The market of plastics used for these purposes in Europe involves hundreds of thousands of hectares and thousands of tons of plastic films per year. The official statistics suggest that although plastics used in agriculture comprise less than $2 \%$ of the total plastics consumption in Europe and $4 \%$ in USA, much more is used in the Mediterranean countries where horticultural crops are intensively produced. However, a very large quantity of plastic is used in agriculture worldwide. In China the greenhouse industry grew rapidly since 1980: in 2002 the area of protected horticulture covered some $1,963,000$ hectares [Jiang 2004] included 700,000 hectares of greenhouse total area. In the north China, where the winters are cold, plastic tunnels are used primarily in the early spring and late autumn. In the south, where the winters are mild, the tunnels can be cultivated all year long [Zhang 2001]. Presently, the protected area for fruit production (peaches, nectarines, grapes, cherries, strawberries and melon) and flowers is not very large, but these crops are very profitable, so for the future a strong increase is expected [Jiang 2004].

The agricultural applications of the plastic films and the relative covered surfaces [CIPA 2006] in the European countries (Tab. 2) are mainly for the production of flowers, ornamentals and vegetables, such as tomatoes, eggplants, peppers, cucumbers, asparagus, melon, watermelon, and strawberries.

\subsection{Current situation of the agricultural plastic products used in Europe}

Plastic materials are widely used in European agri- 


\begin{tabular}{|c|c|c|}
\hline $\begin{array}{l}\text { Protected cultivation films: } \\
\text { - Greenhouse and tunnel } \\
\text { - Low tunnel } \\
\text { - Mulching } \\
\text { - Nursery films } \\
\text { - Direct covering } \\
\text { - Covering vineyards and orchards }\end{array}$ & $\begin{array}{l}\text { Nets: } \\
\text { - Anti-hail } \\
\text { - Anti-bird } \\
\text { - Wind breaking } \\
\text { - Shading } \\
\text { - Nets for olives and nut picking } \\
\text { Piping, irrigation /drainage: } \\
\text { - Water reservoir } \\
\text { - Channel lining } \\
\text { - Irrigation tapes and pipes } \\
\text { - Drainage pipes } \\
\text { - Microirrigation } \\
\text { - Drippers }\end{array}$ & $\begin{array}{l}\text { Packaging: } \\
\text { - Fertilizer sacks } \\
\text { - Agrochemical cans } \\
\text { - Containers } \\
\text { - Tanks for liquid storage } \\
\text { - Crates } \\
\\
\text { Other: } \\
\text { - Silage films } \\
\text { - Fumigation films } \\
\text { - Bale twines } \\
\text { - Bale wraps } \\
\text { - Nursery pots } \\
\text { - Strings and ropes }\end{array}$ \\
\hline
\end{tabular}

TABLE 1 - Applications of plastic in agriculture.

culture because they contribute to increase the quality and the quantity of production.

Their use is continuously diffusing, above all in some agricultural applications, such as covering of greenhouses, tunnels, low tunnels that are continuously increasing, essentially in some Mediterranean countries (Italy, Spain and France).

The same phenomenon characterizes the mulching surfaces, finding positive trends for Italy, Spain and Germany. In detail, in Italy during the last years, the consumption both of plastic films, for greenhouses and tunnel covering and for mulching, and of other agricul-

\begin{tabular}{|c|c|c|c|c|}
\hline Country & $\begin{array}{l}\text { Greenhouses and } \\
\text { large tunnels (ha) }\end{array}$ & $\begin{array}{l}\text { Low tunnels } \\
\text { (ha) }\end{array}$ & $\begin{array}{c}\text { Mulching } \\
\text { (ha) }\end{array}$ & $\begin{array}{l}\text { Direct covers } \\
\text { (ha) }\end{array}$ \\
\hline GERMANY & 700 & 1,000 & 15,000 & 11,200 \\
\hline AUSTRIA & 450 & & & \\
\hline BELGIUM & 350 & 200 & 3,400 & 3,000 \\
\hline BULGARIA & & 2,500 & 13,000 & 500 \\
\hline CYPRUS & 235 & & & \\
\hline DENMARK & 20 & & & \\
\hline SPAIN & 53,235 & 14,641 & 120,039 & 1,400 \\
\hline FINLAND & 200 & & & \\
\hline FRANCE & 9,200 & 15,000 & 100,000 & 11,000 \\
\hline GREECE & 3,000 & 4,500 & 5,000 & 400 \\
\hline HUNGARY & 6,500 & 2,500 & 2,400 & 4,000 \\
\hline ITALY & 25,000 & 26,000 & 85,000 & 12,000 \\
\hline MALTA & 100 & & & \\
\hline NETHERLANDS & 400 & & & 1,300 \\
\hline NORWAY & & & 2,800 & \\
\hline POLAND & 2,000 & 800 & & 4,000 \\
\hline PORTUGAL & 2,700 & 450 & 23,000 & \\
\hline SWEDEN & 60 & & & \\
\hline SWITZERLAND & & & 2,800 & 1,000 \\
\hline CZECH. REP. - SLOVAKIA & 4,900 & & 2,000 & \\
\hline UK & 2,500 & 1,400 & 10,000 & 12,000 \\
\hline UZBEKISTAN & & & 620 & \\
\hline $\begin{array}{l}\text { RUSSIAN FEDERATION and other } \\
\text { EUROPEAN COUNTRIES }\end{array}$ & & & 42,000 & \\
\hline EUROPE & 111,550 & 68,991 & 427,059 & 61,800 \\
\hline
\end{tabular}

TABLE $\quad 2$ - Main agricultural applications of plastics for protected cultivations in Europe. 
tural plastic materials, for vineyard covering, nets, irrigation tapes and pipes, agrochemical containers, has increased (e.g. agrochemical containers, because the chemical protection of cultivations is diffuse; irrigation pipes, because watered fields have increased, etc.).

According to their use, plastic materials (traditional or alternative) are characterized by a basic composition and by additives (Tab. 3 ).

The agricultural areas characterized by a high density of structures for crop protection (greenhouses and tunnel) and/or a wide diffusion of mulching (in greenhouses or in open field) are diffuse on the whole Italian territory with a higher concentration in the southern regions.

Plastic wastes are produced during the whole year, but the period of collection of each stream is different because it depends on the seasonal production of the crops: generally, mulching films are collected in May, June and September, at the end of the crop cycle, while greenhouse covering films in August and September, when the new covering are installed and substitute the old ones.

During their use, plastic materials are contaminated by different impurities, mainly soil and agrochemical particles.

\section{A) Greenhouse covering}

At present the greenhouses, once covered with glass, are more and more covered by plastic materials, as an alternative to glass principally for their cheapness, lightness and large size features; the selection of the plastic material type to be used depends on several factors, mainly the local tradition related both to the latitude and the climatic characteristics and to the protected cultivation value: for cash crops, like ornamentals and flowers, more expensive rigid sheets can be adopted, whereas for lower value cultivations, like vegetable crops, plastic films of about $140 \div 200 \mu \mathrm{m}$ thickness are often preferred, characterized by a long life (3-4 years).

The introduction of plastic films has led to innovative forms of arch-shaped greenhouses characterized by one or more spans (arch-shaped tunnels and multispan tunnels) and steel structures, resulting lighter and cheaper; besides the steel structures permit small structural sections and few fastenings of the covering, causing smaller opaque surfaces and a consequent increase of the solar radiation incoming into the greenhouse.

Greenhouses can be covered by single or double film layers. Double films are spaced by a layer of air,

\begin{tabular}{|c|c|c|c|}
\hline \multirow[t]{2}{*}{$\begin{array}{c}\text { Applications and } \\
\text { basic compositions }\end{array}$} & \multirow{2}{*}{ Additives } & 1999 & 2005 \\
\hline & & consumption $(t)$ & consumption $(t)$ \\
\hline $\begin{array}{l}\text { Greenhouse films } \\
\text { (LDPE, LDPE.IR, EVA, LLDPE) }\end{array}$ & $\begin{array}{l}\text { Anti-fog, Photo-selective, UV stabilizers, Long } \\
\text { Infra-red properties enhancer master-batch }\end{array}$ & 57,000 & 60,000 \\
\hline $\begin{array}{l}\text { Low tunnel films } \\
\text { (LDPE, EVA, LLDPE, PVC) }\end{array}$ & UV stabilizers, Infra-red properties enhancer & 30,000 & 31,200 \\
\hline $\begin{array}{l}\text { Mulching films } \\
\text { (Transparent or black LDPE) }\end{array}$ & Coloured pigments, UV stabilizers, Carbon black & 40,000 & 42,000 \\
\hline $\begin{array}{l}\text { Covering vineyard, orchards } \\
\text { (LDPE, EVA) }\end{array}$ & UV stabilizers, Coloured pigments & - & 25,000 \\
\hline $\begin{array}{l}\text { Nonwoven /Floating covers } \\
(\mathrm{PP}, \text { perforated LDPE) }\end{array}$ & & 2,000 & 2,500 \\
\hline $\begin{array}{l}\text { Nets for collecting } \\
(\mathrm{PP}, \mathrm{HDPE})\end{array}$ & Coloured pigments & 2,000 & 2,000 \\
\hline $\begin{array}{l}\text { Woven nets (hail, wind, bird, shade) } \\
\text { (HDPE) }\end{array}$ & Coloured pigments & 3,000 & 3,300 \\
\hline $\begin{array}{l}\text { Silage films and protective covering } \\
\text { (LDPE) }\end{array}$ & Coloured pigments & 8,000 & 8,500 \\
\hline $\begin{array}{l}\text { Irrigation and drainage (LDPE, } \\
\text { HDPE, PVC, PRFV) }\end{array}$ & Coloured pigments & 67,000 & 91,700 \\
\hline $\begin{array}{l}\text { Other (rigid shhets, pots, twine, etc) } \\
\text { (LDPE, PP, PS, HDPE, PRFV, PVC, } \\
\text { PMMA) }\end{array}$ & Coloured pigments & 69,600 & 91,000 \\
\hline $\begin{array}{l}\text { Pesticides cans } \\
\text { (LDPE, HDPE) }\end{array}$ & Coloured pigments & - & 2,500 \\
\hline $\begin{array}{l}\text { Fertilizers bags } \\
\text { (LDPE, HDPE) }\end{array}$ & Coloured pigments & 12,000 & 12,000 \\
\hline TOTAL & & 284,300 & 369,700 \\
\hline
\end{tabular}

TABLE 3 - Plastic material applications and consumption in Italian agriculture. 
that allow a heating energy saving of $25-30 \%$ if compared to the single film owing to the reduction of conductive, convective and LWIR radiant losses but, on the other hand, a reduction of solar radiation transmittance occurs.

Furthermore, using double film layers, it is possible to obtain better thermal performances than those produced by a covering of single glass layer.

For the inside layer, films of $100 \mu \mathrm{m}$ thickness can be used in order to increase solar transmittance. Double film layers help also to reduce water condensation and the consequent dripping inside greenhouses, that causes harmful effects to the crops, and avoids the thermal inversion of the inside air temperature of 2 - 3 ${ }^{\circ} \mathrm{C}$ that occurs during the clear winter nights inside the unheated greenhouses and tunnels with a single plastic film covering.

The various plastic materials differ in their mechanical properties and in their radiometric characteristics, and the presence of additive compounds in the their chemical composition ensure the material to have thermal, anti-fog or anti-drop characteristics.

The covering materials determine significant microclimatic variations within the protected space, by reducing conductive, convective and radiant losses of energy.

The increase of microclimate thermal conditions in the protected environment by means of the exploitation of the incoming solar radiation, known as the "greenhouse effect", depends on the radiometric properties of the installed cladding materials both in the solar and in the long wave infrared radiation (LWIR) (Fig. 1).
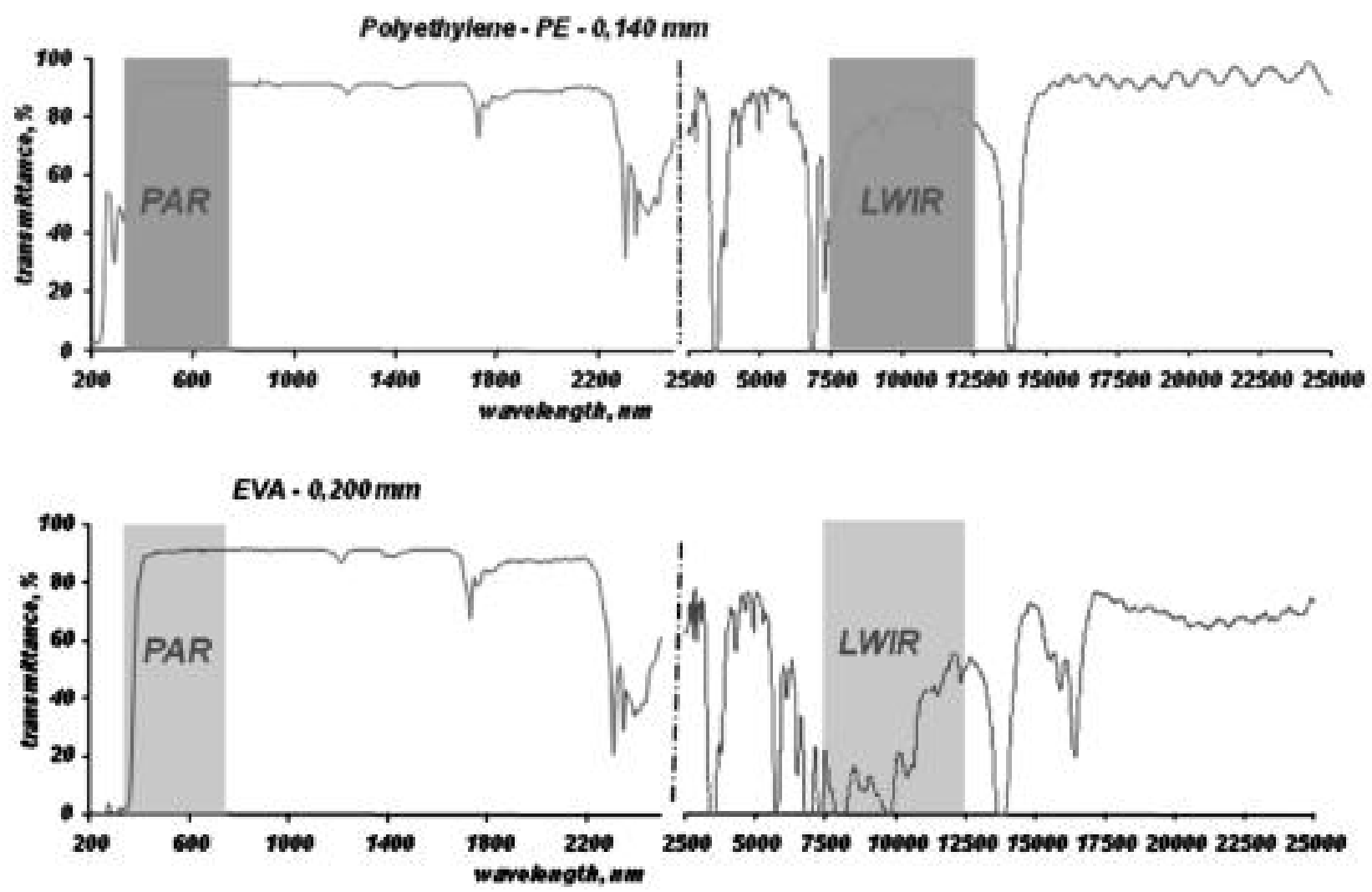

Polycarbonate $\cdot P C=0,850 \mathrm{~mm}$

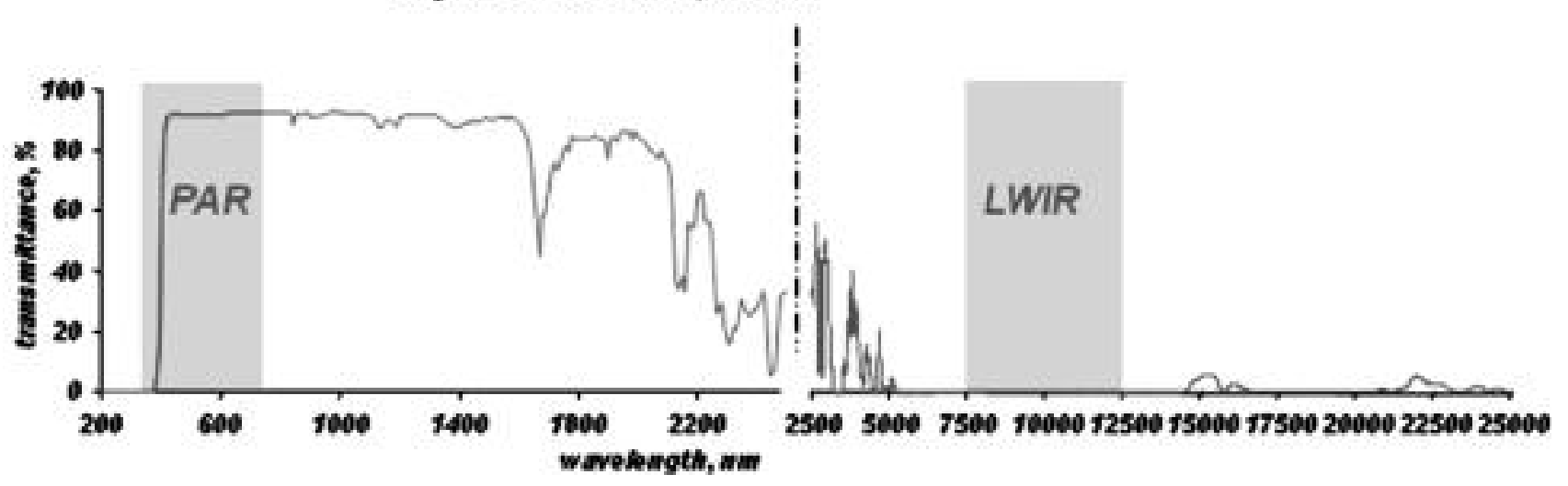

Fig. 1 - Transmittance of LDPE film, EVA film and PC rigid sheet in the range 200-25000 nm. 
The quality of the radiation that the covering material allows to enter the greenhouse is important for evaluating its influence on the growth and development of plants [Kittas 1999].

\section{B) Low tunnels}

Low tunnels consist of small arch-shaped support structures covered by plastic film, so as to realize a protected microclimate suitable for cultivation.

They are usually 50-80 $\mathrm{cm}$ high; during sunny days and the summer season the covering can be easily opened or removed, this being a great advantage that helps the diffusion of these tunnels for protected cultivation. Plastic films of about $60 \div 100 \mu \mathrm{m}$ thickness are generally installed.

\section{C) Mulching}

The mulching technique consists in covering the soil, where cultivations have been planted, with a layer that protects seedlings and young plants. The mulching application contributes to increase soil temperature at the root level thanks to a reduction of water evaporation and of heat loss by radiation and convection, contributing also to the reduction of weed growth and the consequent use of chemicals. In this kind of application plastic has replaced straw or paper, which were used in the past. Nowadays mulching is made of plastic films, transparent or opaque, white or black or coloured, having a small thickness $(20 \div$ $50 \mu \mathrm{m})$, which are mechanically laid on the soil.

Recently, the technique of mulching with transparent large films has also been used in many Mediterranean Countries for soil solarization, in order to obtain, before planting, a partial sterilization of the agricultural soil due to the high temperatures, generated in watered and mulched soil during the summer season thanks to the high solar radiation, which are able to eradicate the main soil-borne pathogens and to devitalize weed seeds. The soil solarization is often used with other disinfecting techniques such as green manure with biocide plants that can increase soil quality. A new mulching technique consists in an application by means of spraying a degradable foaming substance on the soil [Schettini 2008].

\section{D) Temporary coverings of structures for fruit trees}

The technique of temporary coverings of structures for fruit trees has been increasingly used in many Italian Regions; it consists in covering pergola structures for fruit tree specialized cultivations with plastic films or plastic nets, in order to obtain higher daily air temperatures, to protect the cultivation from damages caused by birds as well as to limit the harmful effects due to wind, rain and hail.

In this way, larger fruit tree grown areas are protected, thanks to the advance or delay of the production and harvesting, which enable higher income prices; the most widespread orchards practiced in Italy by using the above technique are vineyard, kiwi, peach-trees and apricot-trees.

\section{E) Nets}

Plastic nets for various agricultural applications are widely used: protection from hail, wind, snow, or strong rainfall in fruit-farming and ornamentals, shading nets also for greenhouse applications during the summer, cooling the inside microclimate. Moreover, nets for the protection against virus-vector insects and birds, as well as for harvesting of small fruits, and postharvesting operations (collecting of cut flowers and drying of fruits) are often used. Nets are also used to shade mushroom-beds and shelters for cattle breeding.

It is very important to evaluate the shading effect of employed nets because it can be considered as a positive effect when the net covering system is used to reduce the incoming solar radiation while in other applications, such as the anti-hail, could produce undesirable consequences modifying the microenvironment, particularly inside brightness and air temperature [Castellano 2008].

Net types are characterized by different structural features, like kinds of threads, fabrics, shape and dimension of fibers and meshing, by physical properties like weight, colours, shading factor, durability, porosity, air permeability and mechanical characteristics such as stress, strength at break and elongation. The most used raw material for agricultural nets is high density polyethylene (HDPE), while polypropylene (PP) is also used as raw materials for nets but, more frequently, for the production of non woven layers [Castellano 2005].

\section{F) Other applications}

Other applications to protect crops with plastic materials are: floating mulch, that is a mulching layer generally made in non-woven fabric laid above the crop; rain shelters, which are unheated greenhouses with large side openings. Other versions of these applications are diffuse depending on the crop cultivation traditions, latitude, climate, etc.

\section{G) Other plastic products used in the agricultural sector}

Other manufactured plastics are used for irrigation and drainage pipes or tapes, pots for ornamental plants and flowers, nursery containers, soilless culture substrate, strings, bags and containers, also for agrochemicals. Plastic films are used even for silage, packaging, transport, storage and sale of agricultural products.

\section{Main traditional "agricultural" polymers}

Around twenty distinct groups of plastics for agricultural use exist, each with various formulations available to enable the best choice for each specific application. In order to produce flexible, semi-rigid and/or rigid materials, the main polymers used in agriculture are the followings:

- Polyethylene (PE) is a thermoplastic polymer be- 
longing to the polyolefin family. PE exists in two main forms, namely high density polyethylene $\left(\mathrm{HDPE}=0.94-0.96 \mathrm{~g} / \mathrm{cm}^{3}\right)$ and low density polyethylene $\left(\mathrm{LDPE}=0.92-0.93 \mathrm{~g} / \mathrm{cm}^{3}\right)$. Also linear low density polyethylene (LLDPE) is used in order to produce film characterized by minimum thickness and high mechanical properties. PE has a wide range of agricultural uses because of its low cost, good workability, high impact resistance, excellent chemical resistance and electrical insulation properties. In particular LDPE is used to produce films (for greenhouses, low tunnels, mulching, silage) and irrigation tapes, while HDPE is generally used to produce pesticide cans, nets and irrigation pipes.

- Polypropylene (PP) is the second most common linear thermoplastic polymer of the polyolefin family. In comparison to low and high density PE, PP has a lower impact strength, but superior working temperature and tensile strength. PP is most widely used as fibres and filaments produced by extrusion and is used in agriculture for piping, sheeting, nets and twines [McEwan, 2002].

- Polyvinylchloride (PVC) is a thermoplastic polymer; it is a vinyl polymer and it is the third most widely produced plastic, after PE and PP. PVC is mainly used in agriculture for irrigation pipes or tubes and semi-rigid sheets for greenhouses cladding. Only a few tons of flexible PVC (films) are still used as covering material for greenhouses.

- Ethylenvinylacetate (EVA) is a copolymer of ethylene and vinyl acetate. The weight percent of vinyl acetate usually varies from 10 to $40 \%$; usually, it is equal $14 \%$ for agricultural films used to cover greenhouses. EVA is a polymer that approaches elastomeric materials in softness and flexibility, yet can be processed like other thermoplastics. The main characteristics of the greenhouse covering film are: elasticity and good resistance to tensile stress, tear and perforation; high transmissivity to the sunlight in the visible light range, especially in the photosynthetic activity range (PAR), 400-700 nm; high capacity to absorb the radiant heat in the LWIR range and to retain them inside the greenhouse during the night time, known as "greenhouse effect"; long lasting of the mechanical properties and transparency.

- Polymethylmethacrylate (PMMA) is an atactic thermoplastic polymer and is the most widely used in the class of polymers known as acrylics. Some characteristic of PMMA are that it has crystal clear transparency in the solar range $(\approx 90 \%)$ and an outstanding resistance to ageing, but it is susceptible to a large number of solvents. PMMA is the most important polymer for the preparation of sheets, corrugated or alveolar, and rods.

- Polycarbonate (PC) is characterized by high transparency in the solar range $(90 \%)$ and lack of colour. Instead, the UV are absorbed, causing the yellowing of the material during ageing; therefore additives are used as stabilizers (e.g. benzotriazole) or protections are applied to the external surface of the PC sheet. There are different PC sheets, single (simple/compact or corrugated) and double layer (alveolar); the last are used as covering of greenhouse when a good thermal insulation is required.

- Glass reinforced polyester (GRP) was largely used in agriculture for greenhouse covering or for containers, but recently its consumption is limited due to ageing problems.

Agricultural use absorbs $2 \%$ of the total plastic demand in Europe [Plastics Europe 2006]. Main agricultural polymers, according to their uses in some European Countries, are reported below.

In Greece most of the agricultural plastics are polyethylene (PE), mainly LDPE, but also LLDPE for films, and HDPE for irrigation pipes and for containers are used, while PP and PVC are rarely used.

In Spain in addition to PE, there is a share of $33 \%$ of polyvinylchloride (PVC) and $6 \%$ of polypropylene (PP) for agricultural plastics. In France in addition to the PE, there is very little use of PVC (less than $1 \%$ ) but there is a large percentage, $30 \%$, of PP. In Italy in addition to the PE, also PVC, PC, PMMA and PP are utilized.

In all the above mentioned countries, up to $10 \%$ of the greenhouse films are made of EVA and sometimes they are co-extruded with three layers made of EVA and LDPE.

\subsection{Lifetime duration of the agricultural flexible plastics (film and net)}

Agricultural films and nets must satisfy mechanical, physical and radiometric requirements to play an optimum role and to be considered suitable materials; all these properties are defined by American and/or European Standards. For example the minimum tensile stress at break is $20 \mathrm{MPa}$ for a film with a thickness $\leq 50 \mu \mathrm{m}$, and the minimum tensile stress at break is $16 \mathrm{MPa}$ when the film thickness is $\geq 50 \mu \mathrm{m}$ [EN ISO 527-3; ASTM 2002].

Regarding lifetime duration, it depends on many factors, such as the polymer (polymeric chain), the thickness, the application to the structures, used additives in compound, use of agrochemicals, exposure period, climate and latitude of the site, etc.

The lifetime duration of agricultural plastic films varies from some months (mulching films) to 3-4 years (greenhouse films), while nets can last 5-10 years and rigid sheets more than 10 years. The expected service life of a film, or a net, can also be reduced by exceptional climatic events, like hail or wind storms. The duration of a plastic covering is related to the climate and the location where the film is exposed, depending on the yearly solar radiation energy, traditionally expressed in kilo Langley/year (kLy/year). Europe is characterized by values varying from 80 $\mathrm{kLy} / \mathrm{year}$, in the northern countries, to $140-160$ $\mathrm{kLy} / \mathrm{year}$ in the Mediterranean ones. 
Different factors may reduce the correlation between the duration of a film used on a greenhouse and the duration of the same film exposed to artificial weathering; among them the use of pesticides containing sulphur, that could inhibit the protective action of HALS, and the contact area of the film with the supporting structure of the greenhouse that causes during sunshine local overheating of the film. This is an important aspect, because it has a direct influence on the duration of the plastic film and the consequent production of agricultural plastic wastes: a different duration of working life affects different quantities of Agricultural Plastic Wastes produced in a year.

\section{Recent innovative agricultural films}

\subsection{Photo-selective and Photo-luminescent plastic films}

Solar radiation is the most important factor for plant growth and productivity. While the energetic use of solar radiation to produce carbohydrates (photosynthesis), the effect of the timing of solar radiation exposure (photoperiod) and the response of the growth direction to solar radiation (phototropism) have been investigated and continue to be studied, less is known about the effects of light radiation spectral composition known as "morphogenetic effects". Vegetative processes such as the growth of shoots and leaves, the development of the photosynthetic apparatus, the reproductive activity such as flower bud initiation, flowering and fruiting are influenced by the photoreceptor phytocrome, a blue-green proteinaceous pigment [Smith 1982; Rajapakse 1999]. Phytocrome exists in two inter-convertible chemical forms: the inactive form absorbs radiation above all in the red wavelengths (Red, 620-700 nm), while the active form absorbs far-red radiation (FarRed, 700-760 nm). In order to verify the possibility to alter the quality of solar radiation, photo-luminescent and photo-selective plastic films have been realized:

- Red and Blue coloured photo-luminescent films have been designed, by adding master-batches able to absorb UV radiation, in order to retransmit it in the wavelength of red (620-700) and blue (440-490 $\mathrm{nm}$ ) radiation and to evaluate the influence of the innovative film on the $\mathrm{B} / \mathrm{FR}$ ratio of the solar radiation.

- Photo-selective green films have been made by adding different percentages of green transparent Vibatan polyethylene in order to evaluate the influence of the film on the R/FR ratio of the solar radiation.

Studies carried out on these innovative films influencing photo-morphogenesis [De Salvador, 2008] show a significant increase of vegetative activities, especially shoot growth, for the crops grown under both the photo-luminescent and the photo-selective films in comparison to the crops grown under LDPE films or in open field.
Moreover new LDPE films with micro-bubbles of $\mathrm{CO}_{2}$ expanded inside the film thickness were produced in order to increase the solar light diffusion and to reduce the transmittance of the Near IR radiation, in case of hot climate greenhouse locations.

\subsection{An alternative to agricultural plastics: bio-based materials}

For an environmentally friendly agricultural activity an alternative strategy to the plastic films produced with fossil raw resources can be represented by biobased agricultural raw materials reducing both the dependence on oil and the effects caused by the increasing of its price. For low environmental impact applications, biodegradable materials for agricultural films are nowadays produced [Briassoulis 2004].

Biodegradable transparent films for low tunnel covering and black or green films for mulching are based on maize starch as raw material (Mater-Bi) and biodegradable polyesters. These biodegradable films were tested and are produced with a thickness ranging $15-60 \mu \mathrm{m}$, respectively for mulching, the thinner, and for low tunnel transparent films, the thicker one.

At the end of their lifetime, biodegradable films can be buried directly in the soil, no removal from the field is required, or disposed in a composting plant. Biodegradable materials are decomposed in the soil by micro-organisms such as bacteria, fungi and algae, and mineralized into $\mathrm{CO}_{2}$ or $\mathrm{CH}_{4}$, water and biomass, without any harmful effects. Biodegradable materials can also be composted with organic materials such as crop residues and manure.

During the experimental tests [Scarascia 2004; Scarascia 2006b] the values of transmittance in the PAR wavelength (400-700 nm) of the low tunnel transparent films ranged from 77 to $80 \%$, while the transmittance in the LWIR wavelength (7500-12500 $\mathrm{nm})$ ranged from 3 to $7 \%$. The average lifespan was of 1-4 months, but mulching films can last 2-6 months, depending on the thickness, the season climate, the wind actions, the application and the stabilizing additives.

The degradation rate observed from the biodegradable residues buried by the tillage in the soil showed that, after one year, less than $4 \%$ of the initial weight of the film remained in the soil and no evidence of eco-toxicity was noticed.

A very limited amount of biodegradable plastic is used in agriculture: at present in Italy, only 4,000 hectares of agricultural soil is covered by biodegradable mulching films of Mater $\mathrm{Bi}$ used for crops with a cycle between 60 days and 6 months. The productive performances are comparable to the traditional LDPE films but the current price is still higher than the LDPE films with the same thickness. If the costs of plastic film collection, disposal and recycling process are taken into account, the price of the bio-based are comparable to the traditional ones.

Also thermo or photo-degradable polyethylene 
products are used in agriculture. Significant use of these products is reported in France and some use in Greece. The marketing of these new products is very strong. These products contain metal components that promote the breaking down of the film into small pieces through exposure to heat or to sun radiation and must not be confused with biodegradable films. The small fragments are mixed with the soil but their lifetime duration is still high and the environmental and toxicological effects are not studied thoroughly.

\section{Agricultural Plastic Waste (APW)}

Agricultural plastics, produced with fossil raw resources, are subjected to degradation due to their exposure to atmospheric agents such as solar radiation, wind, rain, hail, air temperature and humidity, to the installation and utilization conditions, and to the pesticides used during the cultivation period. Plastic degradation results in the production of huge and increasing amounts of plastic waste when the plastics are dismantled [Scarascia 1995; Sica 2008]. The degradation of plastic films occurs mainly when radicals are formed under the effect of ultra-violet solar radiation and leads to the destruction of the polymeric chains. The majority of waste generated from agricultural plastics come from films and, in the Southern European countries, these films come from protected cultivations (greenhouses, low tunnels, mulching and covering) while in the North European countries they come from silage films and wraps (Tab. 4).

Agricultural plastic wastes constitute an environmental and economic problem [Sica 2000], because they may cause severe and diffuse damages to the landscape, the environment, the agricultural soil, the air and to the shallow and deep water if they are not properly managed and if they are abandoned along rivers, or in rural areas or burnt in open air and uncontrolled sites. The emissions of the combustion during uncontrolled burning pollute the air and consist of harmful substances, such as $\mathrm{CO}_{2}, \mathrm{CO}, \mathrm{H}_{2} \mathrm{~S}, \mathrm{SO}_{2}, \mathrm{NH}_{3}$ and dioxin, and are much greater per mass of material burned than the emissions from controlled incineration (e.g., 20 times as for dioxin; 40 times as for particulate matter, Travis and Nixon, 1991) due to inefficiencies of open combustion. Besides, plastic incineration produces large $\mathrm{CO}_{2}$ emissions (about $3.0 \mathrm{Kg}$ of $\mathrm{CO}_{2}$ per $\mathrm{Kg}$ of Polyethylene) therefore, if incineration is uncontrolled, this quantity is completely introduced in the atmosphere with the well-known negative consequences without any exploitation of energy or heat production. Unfortunately, abandonment and burning are practices still frequently used both in Italy and other countries, although they are against the law.

The different strategies to reduce the amount of plastic waste consist in: increasing the lifetime duration of the materials by means of additives and proper applications and installation, reducing the material thickness, introducing and promoting the use of biobased materials.

\section{Agricultural Plastic Waste management}

\subsection{Production and processing scrap}

Plastic waste is generated at all stages in the value chain, from the major production units of the raw materials, through the manufacturing process which converts the plastics into products and components, to the plastic content of discarded articles at the end-of-life. Scrap from the production and processing steps is generally efficiently recovered directly on-site. Plastic scrap leaving the plants, is recovered at a level of around $90 \%$ in all countries, with the majority being

\begin{tabular}{|c|c|c|c|c|c|c|c|}
\hline Country & $\begin{array}{c}\text { SPAIN } \\
(\text { year 2004) }\end{array}$ & $\begin{array}{c}\text { ITALY } \\
(\text { year 2005) }\end{array}$ & $\begin{array}{c}\text { FRANCE } \\
(\text { year 2006) }\end{array}$ & $\begin{array}{c}\text { UK } \\
(\text { year 2003) }\end{array}$ & $\begin{array}{c}\text { GREECE } \\
\text { (years 2002-2003) }\end{array}$ & $\begin{array}{l}\text { FINLAND } \\
\text { (year 2006) }\end{array}$ & $\begin{array}{c}\text { CYPRUS } \\
\text { (year 2007) }\end{array}$ \\
\hline $\begin{array}{l}\text { Total APW } \\
\text { (tons/yr) }\end{array}$ & $\begin{array}{c}\mathbf{7 5 . 4} \\
\text { (Greenhouse, } \\
\text { Low tunnel, } \\
\text { mulching } \\
\text { films) } \\
\end{array}$ & 230 & 170 & 76.1 & 28 & 8.5 & 0.7 \\
\hline Greenhouse film & 41 & 58 & 7.5 & 5 & 3 & & 0.2 \\
\hline Low tunnel film & 5 & 31 & 8 & & 2 & & 0.03 \\
\hline Mulching film & 30 & 42 & 13 & & 4 & & 0.01 \\
\hline Direct Covering & 49 & & & & & & \\
\hline Fertilizers sacks & & 12 & 10 & 12 & 8 & & \\
\hline Pesticide cans & & 2.5 & 6.5 & 2.5 & 0.05 & 1 & \\
\hline
\end{tabular}

TABLE 4 - Yearly agricultural plastic consumption in some European countries and waste generation. 
mechanically recycled. In any case, to choose the most suitable method of disposal, the techniques of Life Cycle Assessment (LCA) are necessary. Life Cycle Assessment is one of the key tools for the implementation of an Integrated Product Policy of all sectors, also agriculture. Life Cycle Assessment according to ISO 14040 allows to efficiently analyze, aggregate and assess environmental impact and resource intensity along the whole life cycle ("from cradle to grave").

\subsection{Post-consumption plastic waste}

Generally the European legislation on waste management is aimed at post-consumer waste from endof-life products such as packaging, automotive, electric and electronic equipment [PlasticsEurope 2006], while few countries, including Italy, have a legislation on agricultural waste management.

In Italy only a part of agricultural plastic waste is collected, transported and recovered in a controlled way by the "PolieCo", the "Italian Consortium for the recycling of the PE materials", except PE packaging, established by law in 1997. As part of their obligation to a sustainable agriculture, the plastic manufacturers, distributors and farmers are involved to ensure the safe disposal of waste caused by agricultural plastic products.

Agricultural plastic waste, such as silage films or greenhouse films, is a good input for mechanical recycling as it is made from a limited range of plastics, mostly polyolefins. The leading countries in terms of quantities are France, Germany, Italy and Spain with recycling rates in the range of $20-30 \%$; in particular, in the year 2005, about $34 \%$ of the total post-consumption agricultural PE was recycled in Italy, according to the Italian Consortium "PolieCo". It appears that Norway had the highest rate, managing to recover and recycle virtually $100 \%$ of agricultural plastic waste [PlasticsEurope 2006].

In France a voluntary collection and recovery scheme for farm crop protection plastic waste started in 2001 and in 2003 a collaborative agreement was carried out by the French Ministry of Ecology for the collection and valorization of agricultural plastic waste.

A Geographical Information System (G.I.S.) ad hoc designed could be a tool suitable for the management of the agricultural plastic waste flux [Scarascia 2008], in order to study: the stream of agricultural plastic waste from the farms to the collection areas, both the yearly quantities of surface (hectares) and the consumption (tons) of agricultural plastics, and the flow of plastic material to direct the stream of agricultural plastic waste from the collection areas towards pre-established recycling firms.

\subsection{Disposal}

A sound procedure for the collection and disposal of this waste can be considered interesting also from an economical point of view, due to the recovery of material or energy that could be obtained [Picuno 1994].

Post-consumer agricultural waste, flexible and rigid, represents a valuable resource in terms of both material and energy. Agricultural plastic waste should then be considered as a "secondary raw material" to be used for in the following processes.

Different recycling strategies have been proposed and are under investigation: mechanical recycling, chemical recycling and energy recovery are at present the most investigated although with different extents of application and different advantages and disadvantages. Mechanical recycling permits an easy reuse of the same material by exploiting conventional equipment, but some loss or reduction of properties must be taken into account. The recovery of plastic materials through chemical recycling gives rise to the production of monomers and then of new, raw polymers and also of chemicals and fuels even though it needs big plants and resources. Energy recovery allows the complete elimination of the material after exploiting its energy content [La Mantia 2002].

LDPE materials (films, bags, pipes, etc) are transported to recycling plants where they are washed, separated manually or through a detector for possible other material (paper, metal, etc.) and then reduced to flakes.

The mechanical properties of the recycled material may also be influenced by the presence of some factors, such as additives: e.g., the addition of starch to LDPE blends increases the tensile strength and the elongation at break and reduces the melt flow index (MFI) values (considered a useful indication for the analysis of the degradation of some polymers as a consequence of reprocessing) [Sica 2008] the characteristics of the regenerated product result in a deterioration both of their mechanical (tensile strength and elongation at break) and radiometric (reduction of the transmissivity in the solar range) properties. In any case the identification of suitable additives to be added to the mixture, or the development of more advanced processes that lead to their better wording, might make mechanical recycling more interesting. Plastic waste is subjected to grinding and milling; later, the shredded material is pelletized, that is placed in a "cubes" press that gives the material a high enough density in order to make it suitable for the subsequent extrusion process. During the pellet phase, the material is forced, through a system of rollers, to cross the holes of a die until it is compacted and takes the form of a cylinder of fixed diameter and length.

Following there is the mixing phase, in a vertical screw mixer, during which the compound is homogenized and simultaneously a dye is added. This mixture feeds the extruder, a worm screw that is put in rotation by a hydraulic motor within an adiabatic cylinder. The friction that develops between the screw and the material produces heat (about $200{ }^{\circ} \mathrm{C}$ ) that causes the fusion of the same material. Due to the rotation of the 
screw, the polymer melt is fed into the cylinder so that, escaping from a die, it is injected into a mold, characterized by a fixed section, until it is filled. Finally, the mold is rotated until it is immersed in a pool of cooling water to allow rapid solidification of the plastic. When this occurs, the profile is removed from the mold by means of a jet of compressed air produced by a compressor mounted on the same machine.

HDPE is generally recycled by granulation, producing flakes. Contaminants are removed by washing and then the flake is separated from other plastic components by means of a float tank. As a result of high costs, coloured HDPE is often not removed and the resulting recycled product has a slight coloration [McEwan 2002]. The recycling of PVC is not as widespread as for other polymers because of the fact that the most part of its applications involve long-term usage and as a result are less likely to become waste products. PVC can be successfully recycled by grinding or by chemical recycling to recover chlorine that can be used in monomer production. There are however few barriers to recycling. Because PVC exists in many forms and colours it is not readily identifiable.

PMMA can be recycled by means of several common techniques. As a result of its tendency to depolymerize, the most common recycling technique is pyrolysis, producing monomer that is then reused for polymerization. The recycling of PMMA consists primarily of industrial scrap. Small amounts of this polymer are also being recovered from automotive scrap, but the recycling of industrial scrap is much more prevalent because the scrap generated by acrylic producers is relatively pure in that it is not in a mixed plastic form. Chemical recycling of PMMA not only aids in the reduction of solid waste in landfills but it also considered economically competitive compared to the cost of virgin raw materials. The thermal depolymerisation of PMMA involves the use of molten metals or metal salts as heat transfer media, dry distillation, superheated steam, extrusion processes and microwave heating [Pilati 2002].

There are many recycling techniques used for PC, depending on the application the resin has been used for it. In case of uses with other material, PC has to be separated from the other component. Recycling by melting is not useful due to the melt and degradation temperatures of PC being close. The most common recycling technique is likely to be granulation.

\section{End life of agricultural plastic waste}

\subsection{Material recovery: mechanical and chemical re- cycling}

The mechanical recycling of polyolefins is a very important part of the recycling industry. Indeed, as virgin poliolefins are mainly processed in the polymer industry, in the same way the large amount of poly- olefins manufacts and the relatively easy collection makes economic recycling possible.

The different types of structures of the commercial PE strongly influence the recycling behavior of these materials. Indeed the presence of branching changes the degradation kinetic and then the final properties of the recycled material after repetitive processing steps. This behavior is particularly important for those plastic materials that are subjected not only to thermo-mechanical degradation during reprocessing operations, but also to some other types of degradation during their lifetime. Indeed, photo-oxidation or other types of degradation induce different structural and, as a consequence, morphological changes depending on the structure of the polyethylene [La Mantia 2002]. The structure of the reclaimed LDPE coming from agricultural films, can be modified because the degradation is usually severe. For example, a dramatic reduction of the elongation at break is possible with the increasing of the exposure time; so, after about one year the ductile polymers become fragile. Of course these results cannot be generalized because they depend on the amount of solar energy, mostly UV radiation, absorbed by the polymer. The level of degradation, and then the level of structural and morphological modification (as remarkable amounts of oxygenated groups as result of photo-oxidative mechanisms) undergone by the polymer during its lifetime, determines the properties of the secondary material [Pospisil 2002]. The main modifications are the increasing of the value of the melt index and a decreasing of the molecular weight; this latter and the presence of less deformable structures reduce the elongation at the break and this premature breaking can decrease the tensile stress [La Mantia 2002]. The important feature to point out is that even if monopolymer blends are made up of two materials with the same chemical composition, but with some differences in molecular weight and chain structure (it is the case of the virgin/recycled homopolymer blends) because the eventual presence of the "alien" chemical group, present in recycled parts owing to photooxidative degradation, can alter properties, making the blend not suitable [Scaffaro 2002]. PE recovered from agricultural uses is a typical example; in fact this material contains an oxygenated group as a result of photooxidation, crosslinks, additives and stabilisers. Moreover, these films include in their formulation other polymers such as ethylene vinyl acetate. Differences in the rheological properties of the virgin $\mathrm{PE}$ and of the recycled PE are also due to the presence of additives that are typically used in films for agriculture. In this case it is clear that even if the two starting materials are thought to be the same PE, they may be significantly different and give rise to incompatible blends [Scaffaro 2002]. It can be concluded that the final properties of the blend depend on the amount of degraded polymer but mainly on the extent of degradation. When degradation of the polymer is limited, good properties can be achieved, but if the degrada- 
tion effects are more pronounced, there is a general worsening of all the properties.

Chemical recycling, also called feedstock or tertiary recycling, is considered the option between mechanical recycling and energy recovery. It is a more valuable recovery solution of the plastic wastes than incineration, and overcomes some of the problems that limit mechanical recycling. Any type of technology that involves controlled chemical reactions during the recycling process may be defined as chemical recycling. This definition includes reactions such as unzipping depolymerisation back to monomers, step degradation to low molecular weight products through well-defined chain linkage fissions, chain extension for molecular weight upgrading, pyrolysis with the formation of a complex mixture of gaseous, liquid and solid products, and reactive blending of different polymers with the formation in situ of block or graft copolymers that can play the role of compatibilisers [Pilati 2002].

Comparing chemical recycling to the mechanical one, it can be said that for the first there is less need for the sorting of raw materials; in fact, it can sometimes be used both for dirty plastic waste whose contamination precludes the possibility of mechanical recycling and for mixed plastic waste, allowing the recovery of valuable products from one or more of the different plastics in the waste. When it is carried out with the recovery of monomers, purification solves any problems, deriving from additives and other contaminants, to be overcome and the pure monomers recovered can be used to produce new virgin polymers. Another advantage of chemical recycling is that the products of the process are easily reintroduced into the production cycle, without any problems of market saturation.

On the contrary, the main disadvantages of chemical recycling processes, with respect to mechanical ones, are usually related to economics; in fact, the value associated with the macromolecular nature of the plastic waste is lost during chemical recycling; when severe conditions, like strong acids or bases and high temperature, are required to destroy the polymer chain, moreover the chemical plants and the unit operations needed to recover polymerisation-grade monomers must require high investment costs and security equipment. It will probably never become a widely used method for the recycling of large amounts of plastic wastes, but it can contribute significantly to solve the problems due to the disposal of plastic waste with the recovery of useful products [Pilati 2002].

\subsection{Energy recovery}

For waste fractions that do not allow further economically sensible material recovery, such as recycling, energy recovery by combustion is probably the only alternative to landfill disposal. This is especially true when dealing with high calorific value waste fractions and low biodegradability, such as plastics (Tab. 5). Highly degraded or soil contaminated plastics, that cannot be mechanically recycled can be successfully used as an alternative fuel in power plants or in cement factories. In energy recovery the plastic behaves as a fuel: 1 ton of plastic gives off as much energy as 1 ton of oil [Barrales-Rienda 2002].

Agricultural plastic waste could make an ideal replacement for regular fuels. By using plastic as fuel, other primary energy sources, such as gas, oil or coal, can be conserved. This therefore fulfills the basic idea of recycling, i.e., to conserve raw materials and reduce waste.

\subsection{Landfill}

Agricultural plastic waste that cannot be subject to the above-mentioned disposal techniques (non-usable waste resulting from recycling processes, waste of energy recovery processes, mulching films with large amount of soil residues, etc.), will be destined for final disposal in landfills.

\begin{tabular}{|l|c|}
\hline \multicolumn{1}{|c|}{ Materials, compounds, fuels } & Calorific value (MJ kg $\left.\mathbf{~}^{-1}\right)$ \\
\hline Polyethylene & 46.0 \\
\hline Polystyrene & 46.0 \\
\hline Polyvinil chloride & 18.9 \\
\hline Paper and wood & $16.0-16.8$ \\
\hline Methanol & 22.7 \\
\hline Natural gas & 53.4 \\
\hline Propane & 50.0 \\
\hline Kerosene & 46.5 \\
\hline Gasoline & 45.9 \\
\hline Gas oil & 45.6 \\
\hline Anthracite & 29.7 \\
\hline Charcoal & 33.7 \\
\hline
\end{tabular}

TABLE 5 - Calorific values of plastic materials, compounds, products and fuels (Barrales-Rienda, 2002). 


\section{Regenerated plastic manufacts}

By means of the mechanical recycling of post consumption agricultural films, it is possible to obtain regenerated granules and/or pellets that can be used for the extrusion of films or profiles, respectively.

Experimental research were carried out in order to investigate the results of mechanical recycling of agricultural films. The agricultural plastic waste should be duly grinded, pelletized, regranulated (Fig. 2) and extruded. Tensile tests (Fig. 3) and radiometric tests (Fig. 4) on recycled films from agricultural regenerated granule were performed.

The results of these tensile tests (Tab. 6) show that the mechanical properties of the recycled films are quite good but below the standards mentioned in paragraph 3.1. so, they need to be improved.

The radiometric properties show a relatively good performance of the transmittance, $75-85 \%$, in the solar wavelength radiation (Fig. 4).

In order to produce rigid plastic profiles agricultural plastic waste should be processed:

- grinded in a hammer pounder, for a first rough chopping; a second blade grinding mill provides fine pounding into flakes;

- pelletized, in order to give to the material enough density to make it suitable for extrusion. The flakes
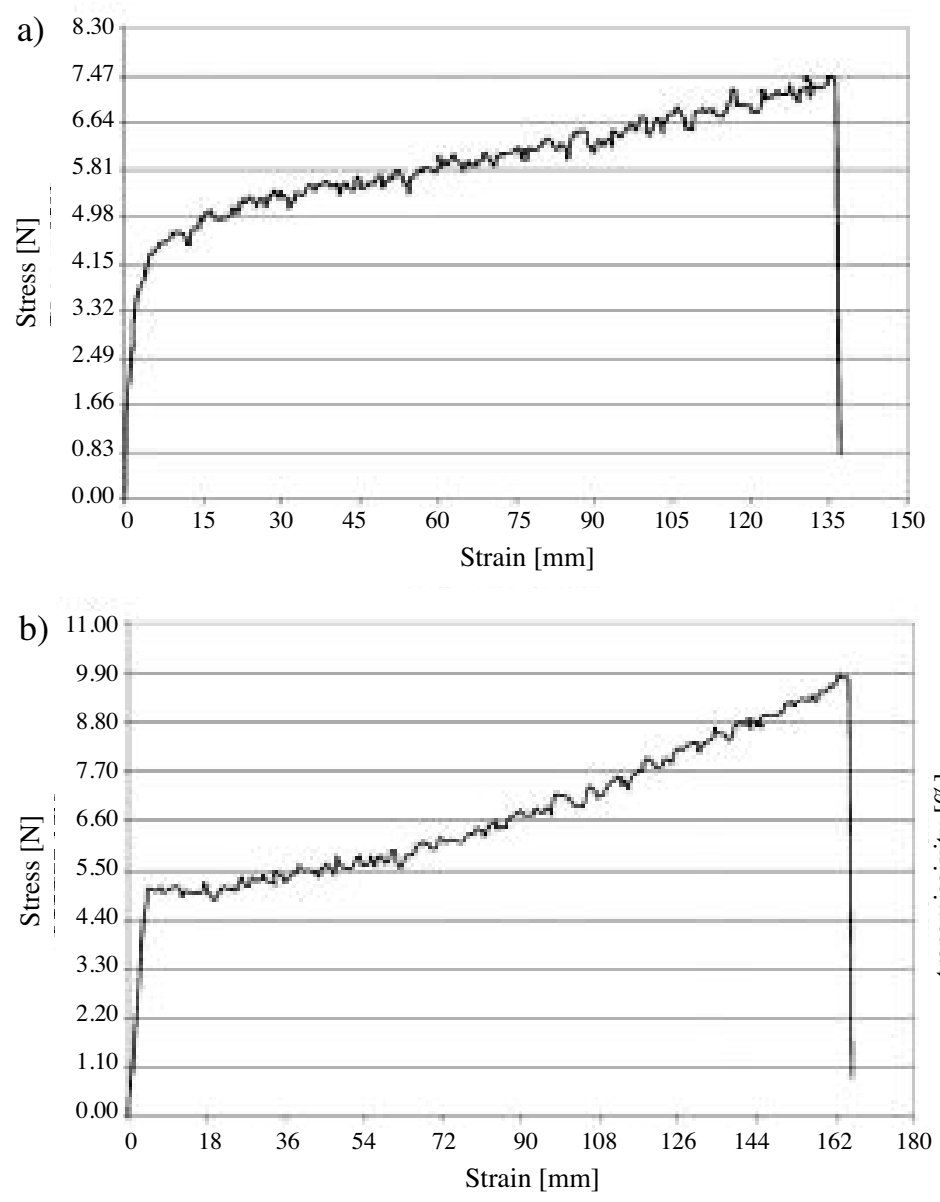

Fig. 3 - Diagram of stress/strain on recycled film: a) parallel direction, b) transverse direction.

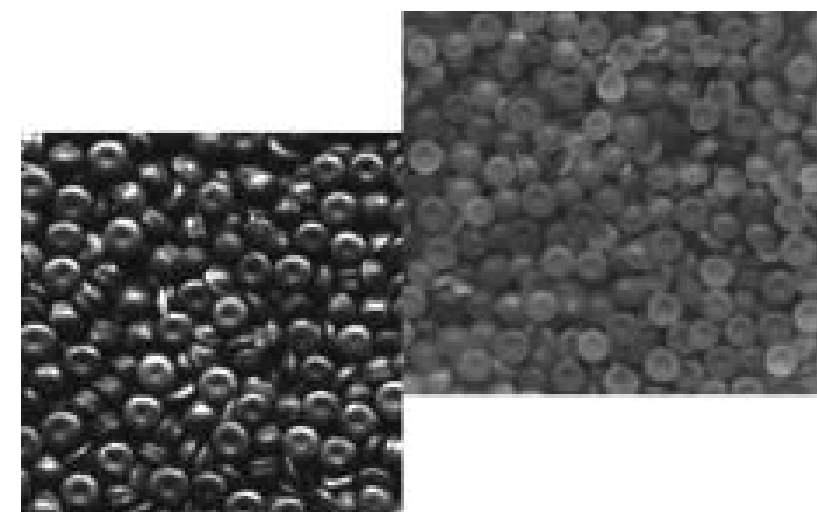

Fig. 2 - Regenerated plastic granules.

are first stocked in silos and then transformed into "pellets" by a cuber machine, where a masterbatch may be added to colour the pellets;

- extruded, for the production of heterogeneous recycled plastic profiles.

With the aim to evaluate the mechanical and physical characteristics of plastic products obtained by recycling different polymeric mixtures of agricultural plastic film, experimental tests were performed on different blends of heterogeneous material. Profiles made of bars with a prismatic shape from recycled agricultural plastic film were produced through mechanical recycling, adding in some cases specific additives in the waste stream, like talc and calcium carbonate(profile density: APW $(\mathrm{PE})=0.84 \mathrm{~g} / \mathrm{cm}^{3}, \mathrm{APW}$ $\left.(\mathrm{EVA})=0.79 \mathrm{~g} / \mathrm{cm}^{3}\right)$.

The results obtained from the tensile compression and bending tests and elastic resistance show that the mechanical characteristics of the recycled plastic bars that were tested, in terms of resistance (Tab. 7) and elasticity could enable an estimation of their possible use in some industrial and/or agricultural sectors, as constructive elements of light structures like fences, vineyard pergola, little shelters, etc. The tensile and compression resistance of the recycled materials are in fact comparable with building materials, like wood.

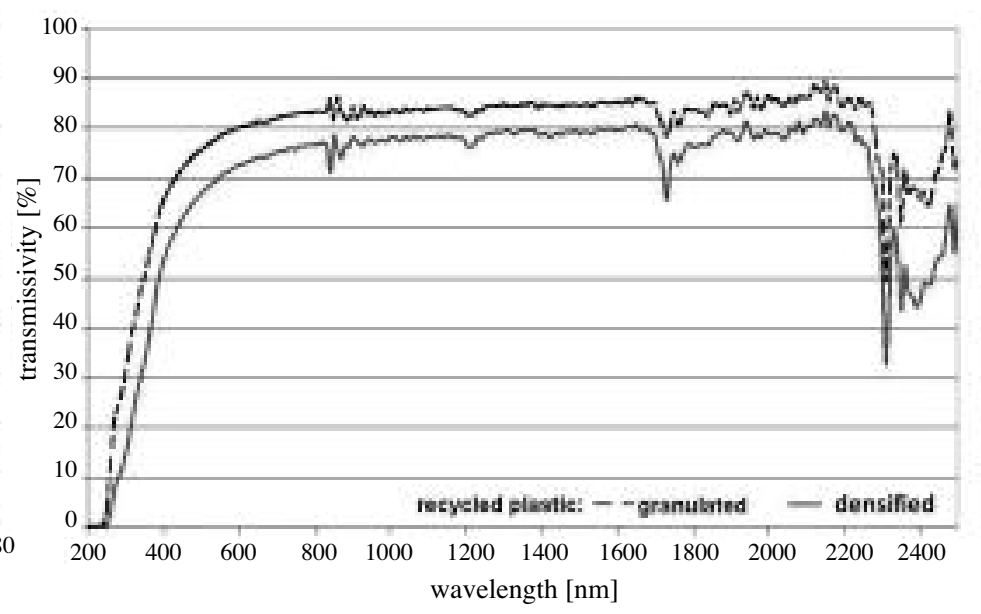

Fig. 4 - Transmittance of two recycled films in the visible and Near IR wavelengths. 


\begin{tabular}{|c|c|c|c|c|c|c|}
\hline & \multicolumn{3}{|c|}{ Granulated material } & \multicolumn{3}{|c|}{ Densified material } \\
\hline & \multicolumn{3}{|c|}{ Blow up Ratio $=2.8 ;$ Strain Ratio $=5.6$} & \multicolumn{3}{|c|}{ Blow up Ratio $=2.8 ;$ Strain Ratio $=2.5$} \\
\hline & $\mu \mathrm{m}$ & $\%$ & $\mathrm{MPa}$ & $\mu \mathrm{m}$ & $\%$ & $\mathrm{MPa}$ \\
\hline Average thickness & 72 & & & 150 & & \\
\hline $\begin{array}{l}\text { Maximum resistance } \\
\text { Machine Direction }\end{array}$ & & & 15 & & & 13 \\
\hline $\begin{array}{c}\text { Elongation at the break } \\
\text { Machine Direction }\end{array}$ & & 304 & & & 313 & \\
\hline $\begin{array}{l}\text { Maximum resistance } \\
\text { Transverse direction }\end{array}$ & & & 19 & & & 14 \\
\hline $\begin{array}{l}\text { Elongation at the break } \\
\text { Transverse direction }\end{array}$ & & 380 & & & 385 & \\
\hline
\end{tabular}

TABLE 6 - Mechanical properties of the recycled films.

\begin{tabular}{|l|c|c|c|c|c|c|}
\hline \multirow{3}{*}{ Test } & \multicolumn{2}{|c|}{$\mathrm{APW}(\mathrm{A})$} & \multicolumn{2}{c|}{$\mathrm{APW}+\mathrm{CaCO}^{3}(\mathrm{~B})$} & \multicolumn{2}{c|}{$\mathrm{APW}+\operatorname{talc}(\mathrm{C})$} \\
\cline { 2 - 7 } & $\begin{array}{c}\sigma_{\max } \\
(\mathrm{MPa})\end{array}$ & $\begin{array}{c}\sigma_{e} \\
(\mathrm{MPa})\end{array}$ & $\begin{array}{c}\sigma_{\max } \\
(\mathrm{MPa})\end{array}$ & $\begin{array}{c}\sigma_{e} \\
(\mathrm{MPa})\end{array}$ & $\begin{array}{c}\sigma_{\max } \\
(\mathrm{MPa})\end{array}$ & $\begin{array}{c}\sigma_{e} \\
(\mathrm{MPa})\end{array}$ \\
\hline Tensile & $10.60 \pm 0.42$ & $6.31 \pm 0.64$ & $11.90 \pm 0.45$ & $6.91 \pm 0.60$ & $13.08 \pm 0.84$ & $5.03 \pm 0.37$ \\
Compression & - & $5.17 \pm 0.14$ & - & $6.04 \pm 0.33$ & - & $7.26 \pm 0.35$ \\
Bending & - & $5.45 \pm 0.35$ & - & $6.75 \pm 0.74$ & - & $7.01 \pm 0.73$ \\
\hline
\end{tabular}

TABLE 7 - Values of the maximum resistance and elastic resistance of three recycled plastic materials.

\section{Conclusions}

Agricultural plastics have been diffused worldwide in the last 50 years thanks to numerous properties such as versatility, lightness, and low cost. Plastic materials in agriculture contribute to increase the yield, the quality of production, the climate growing conditions and permit to realize an earlier harvest, a reduction of pesticides, crop protection, a reduction of water consumption and irrigation optimization, and packaging of agro-food products. They have also provided a more efficient use of farm land.

The consequences of the large amount of agricultural plastics used are the dependence on oil production and the production of waste that, if not properly collected, treated and recycled, pollute the rural areas and release harmful substances in the environment. Sometimes plastic waste is illegally burned, abandoned or ploughed in open field. When burned, it can release many pollutants, which then can enter the food system at the base of the food chain.

Therefore, the strategies to reduce the environmental effects of the use of plastics in agriculture are: a correct procedure for the collection, disposal and recycling of post-consumption plastics; the increase of the lifetime duration of the materials by means of additives and proper applications and installation; the reduction of the material thickness; the introduction and promotion of bio-based materials: biodegradable materials will represent an environmental friendly so- lution for the problem of the disposal and management of agricultural plastic waste.

\section{References}

ASTM D 882. Standard test methods for tensile, properties of thin plastic sheeting, 2002.

Barrales-Rienda J. M. Energy recovery from plastic materials - Handbook of Plastic Recycling, ed. Francesco La Mantia Rapra Technology, 2002, Shawbury, U. K., 337410.

Briassoulis D. An overview on the mechanical behaviour of biodegradable agricultural films. - Journal of Polymers and the Environment, 2004, 12(2), 65-81.

Castellano S., Russo G. Reti in plastica per l'agricoltura: modalità d'uso, materiali, proprietà fisiche. Proceedings of IV AIIA Congress: Agricultural Engineering for sustainable growth in Mediterranean Area, Catania, Italy, 2005, 1-12.

Castellano S., Candura A., ScarasciaMugnozza G. Relationship between solidity ratio, colour and shading effects of agricultural nets. Acta Horticolturae, 2008, 801(1), 253258.

De Salvador F.R., Scarascia-Mugnozza G., Vox G., Schettini E., Mastrorilli M., Bou Jaoudé M. Innovative photoselective and photoluminescent plastic films for protected cultivation. Acta Horticolturae, 2008, 801(1), 219-226.

EN ISO 527-3 Cor 1-1998/Cor 2:2001. Plastics - Determination of tensile properties. Part 3: Test conditions for films and sheets, 1995. 
Jiang, W. J., Qu D.Y., Mu D., Wang L.R. Protected cultivation of horticultural crops in China. Horticultural Reviews, 2004, 30, 115-162.

Jiang W. J., Yu H. J. Present situation and development perspectives of protected horticulture in China, Proceedings of the International Workshop: La produzione in serra dopo l'Era del Bromuro di metile, Comiso, Italy, 2004, 233-240.

Kittas C., Baille A., Giaglaras P. Influence of covering material and shading on the spectral distribution of light in greenhouses, Journal of Agricultural Engineering Research, 1999, 73, 341-351.

La Mantia F. P. Handbook of Plastic Recycling, Properties - Reprocessing Behaviour of Recycled Plastic, ed. Francesco La Mantia Rapra Technology, 2002a, Shawbury, U. K., 127-147.

La Mantia, F.P. Handbook of Plastic Recycling, ed.: Francesco La Mantia Rapra Technology, 2002b, Shawbury, U. K..

McEwan I., Arrighi V., Cowie J.M.G. Structure and properties of commonly recycled polymers, Handbook of Plastic Recycling, ed. Francesco La Mantia Rapra Technology, 2002, Shawbury, U. K., 1-22.

Picuno P., Scarascia-Mugnozza G. The management of agricultural plastic film wastes in Italy. Proceedings of the International Agricultural Engineering Conference, Bangkok (Thailand), 1994, 797-808.

Pilati F., Toselli M. Chemical recycling, Handbook of Plastic Recycling, ed. Francesco La Mantia Rapra Technology, 2002b, Shawbury, U. K., 297-336.

PlasticsEurope An analysis of plastics production, demand and recovery in Europe, 2006, http://www.plasticseurope.org/

Pospisil J., Nespurek S., Horak Z., La Mantia F. P. Upgrading of Recycled Plastics, Handbook of Plastic Recycling, ed. Francesco La Mantia Rapra Technology, 2002b, Shawbury, U. K., 221-244.

Rajapakase N.C., Young R.E., McMahon M.J Oi R. Plant height control by photoselective filters: current status and future prospects, HortTechnology, 1999, 9(4), 618624.

Scaffaro R., La Mantia F. P. Virgin/Recycled Homopolymer Blends, Handbook of Plastic Recycling, ed. Francesco La Mantia Rapra Technology, 2002, Shawbury, U. K., 195-219.

Scarascia-Mugnozza G., Sustainable greenhouse production in Mediterranean climate: a case study in Italy. Medit, 1995, 6 (4), 48-53.

Scarascia-Mugnozza G., Schettini E., Vox G., Effects of solar radiation on the radiometric properties of biodegradable films for agricultural applications, Biosystems Engineering, 2004, 87(4), 479-487.

Scarascia-Mugnozza G., Picuno P., Sica C., Innovative solution for the management of the agricultural plastic waste, Proceedings of World Congress Agricultural Engineering for a Better World, Bonn, Germany, 2006a.

Scarascia-Mugnozza G., Schettini E., Vox G., Malinconico M., Immirzi B., Pagliara S., Mechanical properties de- cay and morphological behaviour of biodegradable films for agricultural mulching in real scale experiment. Polymer degradation and stability, 2006b, 91(11), 28012808.

Scarascia-Mugnozza G., Sica C., Picuno P., The Optimisation of the Management of Agricultural Plastic Waste in Italy Using a Geographical Information System. Acta Horticolturae, 2008, 801(1), 219-226.

Schettini E., Vox G., Candura A., Malinconico M., Immirzi B., Santagata G. Starch-based films and spray coatings as biodegradable alternatives to LDPE mulching films, Acta Horticolturae, 2008, 801(1), 171-179.

Sica C., Picuno P., Scarascia-Mugnozza G., Mechanical characterization of recycled agricultural plastic materials, Proceedings of AgEng 2008: Agricultural and Biosystems Engineering for a Sustainable World, Hersonissos, Crete, Greece, 2008.

Sica C., Environmental problems connected to the use of plastic materials in protected cultivation, Ph.D. dissertation, The University of Basilicata, Potenza, Italy, 2000.

Sica C., Picuno P., Scarascia Mugnozza G., Mechanical characterization of recycled agricultural plastic materials. Proceeding of the AgEng 2008 Agricultural and Biosystems Engineering for a Sustainable World, Hersonissos, Crete-Greece, 23-25 June 2008.

Smith H., Light quality, photoperception, and plant strategy. Ann. Reviews of Plant Physiology 1982, 33, 481-518.

Zhang Z.H., Li J.W., Present situation and discussion on protected horticulture of China. China Vegetables, 2001, $3,1-4$.

\section{SUMMARY}

The world consumption of plastics in agriculture amounts yearly to 6.5 million tons. In addition to conventional polymers used in agriculture for greenhouses and mulches such as PE, PVC, EVA, photo-selective and luminescent polymers have been used, in order to improve the quality of crops. For the same reason plastic nets are used mainly in countries with tropical and Mediterranean climates. For an environmentally friendly agricultural activity, an alternative strategy can be represented by bio-based agricultural raw materials. For low environmental impact applications, biodegradable materials for agricultural films are nowadays produced. An overview of the main methods for the disposal and recycling of plastic materials are presented with the results of mechanical and radiometric tests on recycled plastics. The strategies to reduce the burden of plastics in agriculture are: a correct procedure for the collection, disposal and recycling of post-consumption plastics; the increase of lifetime duration and performance; and the introduction and promotion of bio-based materials.

Keywords: Agricultural plastic materials, plastic material properties, plastic waste management. 